\title{
Advances in Acute Myeloid Leukemia Genomics, Where Do We Stand in 2018?
}

\author{
Yazan F. Madanat, Matt E. Kalaycio, Aziz Nazha
}

Leukemia Program, Department of Hematology and Medical Oncology, Taussig Cancer Institute, Cleveland Clinic, Cleveland, OH, USA

\author{
Correspondence: \\ nazhaa@ccf.org \\ Tel.: + 12164457009 \\ Fax.: + 12164449464
}

Received: 15 October 2018

Accepted: 27 February 2019

Key Words: AML - NGS, Biology • Myeloid - Mutation.

\begin{abstract}
The aim of this review is to summarize the data on commonly mutated genes and genomic pathways in acute myeloid leukemia (AML) with a focus on recently approved targeted therapies. AML is a heterogeneous disease with recurrent cytogenetic and genomic abnormalities that define the disease biology and pathogenesis. Classification of the disease categories and their prognostication was updated in the past 2 years to reflect the most recent advances in understanding the complex disease biology of AML. This review highlights major updates in the World Health Organization classification, including cytogenetic re-classifications, provisional entities, and updates to the European Leukemia Net (ELN) AML risk group stratification. An overview of pivotal studies that used novel sequencing techniques to define the mutational landscape of AML is also provided. In these studies, mutations are classified into subgroups based on functional pathways and are used to understand various interactions and mutual exclusivity of some mutations, suggesting important roles in disease evolution and AML pathogenesis. The complex interactions between mutations can dictate outcomes as well as possibly predict disease phenotypes after correcting for clinical variables. Conclusion. Genomic testing in AML using next generation sequencing has become widely available and a new standard of care for all patients. Therefore, it is vital to use novel methods to incorporate these data in clinical decision making.
\end{abstract}

\section{Introduction}

Acute myeloid leukemia (AML) is a clonal hematopoietic disorder affecting the myeloid cell lineage and is characterized by the expansion of undifferentiated immature myeloid precursors, which result in rapid progression of peripheral cytopenias and bone marrow failure (1). Cytogenetic and molecular heterogeneity can define AML phenotype and affect disease classification, prognosis, response to therapy, and treatment strategy (2). Recent advances in sequencing techniques have allowed the incorporation of genomic abnormalities in decision-making, diagnosis, and changes in treatment recommendations for AML patients $(3,4)$. Updates to the World Health Organization (WHO) 2016 criteria for AML classification and consensus guidelines have incorporated genomic data into AML classifications and prognostic systems $(2,5)$. Genomic data can also be used to evaluate minimal residual disease (MRD), identify specific targets for therapy such as FLT3 and IDH1/IDH2 inhibitors, and develop novel targeted therapies.

In this review, we discuss the genomic landscape of AML and the impact of the 
commonly mutated genes and pathways on AML biology and prognosis.

\section{AML Classifications Cytogenetic Characterization}

Cytogenetic analysis remains one of the most important diagnostic and risk stratification tools in AML. Specific balanced translocation or inversions have been described in AML and can be used as both diagnostic and prognostic tools. These abnormalities include:

- AML with $\mathrm{t}(8 ; 21)(\mathrm{q} 22 ; \mathrm{q} 22.1)$; RUNX1RUNX1T1,

- AML with inv(16)(p13.1q22) or $\mathrm{t}(16 ; 16)$ (p13.1;q22); CBFB-MYH11,

- APL with PML-RARA,

- AML with $\mathrm{t}(9 ; 11)(\mathrm{p} 21.3 ; \mathrm{q} 23.3)$; MLLT3KMT2A,

- AML with $\mathrm{t}(6 ; 9)(\mathrm{p} 23 ; \mathrm{q} 34.1) ; \quad D E K-$ NUP214 and

- AML with inv(3)(q21.3q26.2) or $\mathrm{t}(3 ; 3)$ (q21.3; 26.2 ).

The detection of some of these abnormalities (translocation $(8 ; 21)$, inversion 16/t $(16 ; 16)$ and AML with PML-RARA) were recognized by the WHO classification as sufficient to diagnose AML even in the absence of bone marrow blasts of $\geqq 20 \%$. In the 2016 WHO classification, a new provisional entity was added to recognize AML with BCR-ABL1 (5).

Although the distinction between de novo AML with $B C R-A B L 1$ vs. blast phase chronic myeloid leukemia (BP-CML) is difficult, data suggest that the deletion of specific genes such as IKZF1, CDKN2A, T cell receptor genes, and immunoglobulins may support a de novo AML diagnosis over BP-CML $(6,7)$. Additionally, the $2016 \mathrm{WHO}$ refined the definition of AML with myelodysplasiarelated changes (AML-MRC); patients diagnosed with AML-MRC must have $\geq 50 \%$ of dysplastic cells in at least 2 cell lines, have a history of myelodysplastic syndrome or have specific cytogenetic abnormalities that define this disease entity. Of note, patients who meet dysplastic marrow criteria but concurrently carry an NPM1 or bi-allelic CEPBA mutation, are not classified as AMLMRC. The AML-MRC cytogenetic abnormalities include 3 broad categories: complex karyotype, i.e. $\geq 3$ abnormalities; unbalanced karyotypic abnormalities, such as monosomy 7 or 13; and balanced abnormalities as $\mathrm{t}(11 ; 16)$ or $\mathrm{t}(3 ; 21)$ amongst others $(5)$. Additionally, minor updates in the WHO classification included renaming the $M L L$ gene $K M T 2 A$, as well as recognizing that inv(3) (q21.3q26.2) or $\mathrm{t}(3 ; 3)(\mathrm{q} 21.3 ; \mathrm{q} 26.2)$ is merely a gene rearrangement, without a gene fusion. AML with $\operatorname{inv}(3)$ or $t(3: 3)$ was noted to be associated with GATA2/MECOM and was shown to have aberrant expression of the stem cell regulator ETV1. Both of these 3q gene rearrangements reposition a GATA2 enhancer and lead to ETI1 activation/MECOM expression and functional GATA2 haploinsufficiency. These studies showed how the repositioning of a single gene enhancer leads to AML development $(8,9)$.

The above cytogenetic abnormalities are found in approximately $20-30 \%$ of AML patients, and although they are grouped together, they have significant heterogeneity in their outcomes. Significant advance have been made in our understanding of the genomic landscape of AML since the completion of the human genome sequencing project. These advances have led to the recognition of several somatic mutations that play an important role in AML pathogenesis, prognosis, and the development of targeted therapies.

\section{Genomic Landscape of AML}

Several large scale genomic studies that included whole genome sequencing (WGS), whole exome sequencing (WES), RNA sequencing and other sequencing technolo- 
gies have helped define the genomic landscape of AML (10-12).

In a study of 200 de novo AML samples from the Cancer Genome Atlas Project, analysis of WGS, WES, RNA and microRNA sequencing and DNA methylation identified at least one driver mutation in each AML sample and highlighted the complex interplay between the genomic abnormalities in each sample (12). Somatic mutations were classified into 9 functional groups in decreasing frequency (see Table 1).

In this study, mutational co-occurrence and exclusivity were investigated. Transcription factor fusions genes such as $P M L$ RARA, MYH11-CBFB, and MLL containing fusion were found to be mutually exclusive of DNMT3A, NPM1, CEPBA, IDH1, IDH2 and $R U N X 1$ mutations. These relationships suggest that such mutations may carry similar functions in AML initiation to fusion genes. Additionally, RUNX1 and TP53 mutations were noted to be mutually exclusive of FLT3 and NPM1 mutations. Mutual exclusivity was found within each biologic/ functional gene group such as mutual exclusivity within cohesin complex genes, spliceosome proteins, signaling proteins, and histone-modifying proteins. These findings suggested that a single mutation in each of these pathways is adequate for AML pathogenesis. Clonal evolution plays a significant role in AML relapse and resistance to cytotoxic chemotherapy (12).

In a larger cohort of approximately 1500 AML patients, 5234 driver mutations were identified involving 76 genes, of those, point mutations accounted for the majority of alterations in $73 \%$ of the cases. Furthermore, $86 \%$ of samples had 2 or more driver mutations. A Bayesian model was used to reclassify AML into subtypes based on mutual exclusivity and co-occurrence of mutations. Eleven subtypes were identified, these include:

- NPM1-mutated AML (27\% of cohort),

- AML with mutated chromatin and/or RNA-splicing genes (18\%) which include (RUNX1, MLL, SRSF2, ASXL1, STAG2),

- AML with TP53 mutations and/or chromosomal aneuploidy (13\%),

- AML with inv(16)(p13.1q22) or t(16;16) (p13.1;q22); CBFB-MYH11 (5\%),

- AML with biallelic CEBPA mutations $(4 \%)$,

- AML with $\mathrm{t}(15 ; 17)(\mathrm{q} 22 ; \mathrm{q} 12) ; \quad P M L-$ RARA (4\%),

- AML with $\mathrm{t}(8 ; 21)(\mathrm{q} 22 ; \mathrm{q} 22) ; \quad R U N X 1-$ RUNX1T1 (4\%),

- AML with MLL fusion genes; $\mathrm{t}(\mathrm{x} ; 11)$ (x;q2) (3\%),

- AML with inv(3)(q21q26.2) or $\mathrm{t}(3 ; 3)$ (q21;q26.2); GATA2, MECOM(EVI1) (1\%),

Table 1. Genomic Functional Groups and Frequency in AML*

\begin{tabular}{lll}
\hline Functional Group & Gene & Percentage $^{+}$ \\
\hline Signaling genes & FLT3, KIT, KRAS, NARS, PTPN11 & 59 \\
\hline DNA-methylation genes & DNMTA3/B, DNMT1, TET1, IDH1, IDH2 & 44 \\
\hline Chromatin modifying genes & KMT2A fusions, ASXL1, EZH2, KDM6A & 30 \\
\hline Nucleophosmin gene & NPM1 & 27 \\
\hline Transcription-factor genes & RUNX1, CEBPA & 22 \\
\hline Transcription-factor fusions & PML-RARA, RUNX1-RUNX1T1, MYH11-CEBFB & 18 \\
\hline Tumor-suppressor genes & TP53, WT1, PHF6 & 16 \\
\hline Spliceosome-complex genes & SF3B1, SRSF2, U2AF1, ZRSR2 & 14 \\
\hline Cohesin-complex genes & STAG2, RAD21, SMC3/5 & 13 \\
\hline
\end{tabular}

*Adapted from Cancer Genome Atlas Project (12); ${ }^{\dagger}$ Frequency in Cohort. 
- AML with IDH2R172 mutations and no other class-defining lesions (1\%) and

- AML with $\mathrm{t}(6 ; 9)(\mathrm{p} 23 ; \mathrm{q} 34) ; \quad D E K-$ NUP214 (1\%).

However $11 \%$ of patients had AML driver mutations without a detected classdefining lesion and $4 \%$ had AML without a detected mutational driver. Only $4 \%$ of patient samples met criteria for 2 or more genomic subgroups, most of which fell in the TP53-aneuploidy and chromatin-spliceosome subgroups. The study also showed specific clinical characteristics and different outcomes for each of the subgroups. As expected, the TP53-aneuploidy subgroup had dismal outcomes. Patients in the chromatin-spliceosome group had lower white blood cell and blast counts, were older and had low responses and higher relapses leading to poor outcomes as well. Although patients in the $I D H 2^{\mathrm{R} 172}$ subgroup constituted only $1 \%$, their outcomes were better and similar to NPM1-mutated AML. In that cohort, mutations in DNMT3A, ASXL1, $I D H 1 / 2$, and TET2 genes were often acquired early and often found in association with other genetic abnormalities, suggesting that they are not likely driver mutations of AML, however they are mutations that confer an increased risk for clonal hematologic disorders (11).

In an analysis that compared the mutational profile of patients with de novo AML to therapy related and secondary AML, spliceosome mutations (SRSF2, SF3B1, U2AF1, ZRSR2) and mutations in ASXL1, EZH2, $B C O R$, or STAG2 were $>95 \%$ specific to define secondary AML compared to de novo, but in this study the analysis was not adjusted for cytogenetics and other important clinical variables (13). In another study of 465 patients with secondary and primary AML, clinical variables such as age, cytogenetics, and WBC changed the specificity of some of the mutations to AML phenotype and changed the impact of these mutations on outcomes suggesting that other clinical variables should be taken into account when analyzing genomic data (14). Mutations in AML can be categorized and affect several cellular pathways (Table 1).

\section{FLT3}

FMS-like tyrosine kinase 3 (FLT3) is a receptor tyrosine kinase and gene mutations are found in up to $30 \%$ of AML patients. There are 2 main types of mutations in FLT3, internal tandem duplications (FLT3ITD), which are more common and occur in the juxtamembrane domain of the receptor in about $25 \%$ of AML, and point mutations in the activation loop of the tyrosine kinase domain (FLT3-TKD) in about 5-7\% of AML (15). The impact of each mutation on outcomes is different; where FLT3-ITD mutations have adverse outcomes in AML with normal karyotype, whereas FLT3-TKD mutations have a controversial prognostic value, likely secondary to its lower frequency and smaller number of patients in studies to date. Importantly, incorporating FLT3ITD allelic ratio plays a role in re-classifying disease risk in AML as well as the co-occurrence of NPM1 mutation per the ELN criteria discussed below (2).

In 2017, the U.S. Food and Drug Administration (FDA) granted regulatory approval for midostaurin, a FLT3 inhibitor, for newly diagnosed patients with FLT3-mutated AML patients during induction and consolidation chemotherapy (Figure 1A). The phase III randomized clinical trial that led to its approval was performed over a decade, accruing a total of 717 patients. The overall survival was significantly longer in the midostaurin group than in the placebo group with a hazard ratio for death of $0.7895 \%$ CI, 0.63 to 0.96 ; onesided $\mathrm{P}=0.009$ by stratified score test (16). This can be used as a bridge to transplant, however it is not yet approved in the posttransplant maintenance setting (Table 2). 
Table 2. Targeted Therapies in AML

\begin{tabular}{|c|c|c|c|c|c|c|}
\hline Drug & $\begin{array}{l}\text { Mechanism } \\
\text { of action }\end{array}$ & $\begin{array}{l}\text { FDA Status/Date } \\
\text { of Approval }\end{array}$ & $\begin{array}{l}\text { Newly diagnosed } \\
\text { vs R/R AML }\end{array}$ & $\begin{array}{l}\text { Number } \\
\text { Of Patients }\end{array}$ & $\begin{array}{l}\text { Trial } \\
\text { Phase }\end{array}$ & Outcomes \\
\hline Midostaurin & $\begin{array}{l}\text { FLT3 } \\
\text { Inhibitor }\end{array}$ & $\begin{array}{l}\text { Approved } \\
4 / 28 / 2017\end{array}$ & Newly Dx & $\begin{array}{l}717(360 \\
\text { midostaurin } \\
\text { arm) }\end{array}$ & Phase III & $\begin{array}{l}\text { mOS } 74.7 \mathrm{~m} \text { vs } \\
24.5 \mathrm{~m} \text { for } \mathrm{PL} \text {. } \\
\text { HR for death, } \\
0.78 ; \mathrm{P}=0.009\end{array}$ \\
\hline Gilteritinib & $\begin{array}{l}\text { FLT3 } \\
\text { Inhibitor }\end{array}$ & $\begin{array}{l}\text { Approved } \\
11 / 28 / 2018 \\
\text { (Interim analysis) }\end{array}$ & $R / R$ & $\begin{array}{l}138 \\
\text { (Gilteritinib } \\
\text { arm) }\end{array}$ & Phase III & CR/CRh 21\% \\
\hline Quizartinib & $\begin{array}{l}\text { FLT3-ITD } \\
\text { Inhibitor }\end{array}$ & $\begin{array}{l}\text { Breakthrough } \\
\text { designation } \\
8 / 1 / 2018\end{array}$ & $R / R$ & $\begin{array}{l}367 \text { (245 } \\
\text { Quizartinib } \\
\text { arm) }\end{array}$ & Phase III & $\begin{array}{l}\text { mOS } 27 \text { wks } \\
\text { vs } 20.4 \text { wks for } \\
\text { standard of care }\end{array}$ \\
\hline Enasidenib & $\begin{array}{l}\text { IDH2 } \\
\text { Inhibitor }\end{array}$ & $\begin{array}{l}\text { Approved } \\
8 / 1 / 2017\end{array}$ & $R / R$ & 176 & Phase I/II & $\begin{array}{l}\text { ORR/CR } 40 \% / 19 \% \\
\text { mOS } 9.3 \mathrm{~m}\end{array}$ \\
\hline Ivosidenib & $\begin{array}{l}\text { IDH1 } \\
\text { Inhibitor }\end{array}$ & $\begin{array}{l}\text { Approved } \\
7 / 20 / 2018\end{array}$ & $R / R$ & 179 & Phase I/II & ORR/CR 42\%/24\% \\
\hline $\begin{array}{l}\text { Gemtuzumab } \\
\text { ozogamicin + } \\
\text { chemotherapy }\end{array}$ & $\begin{array}{l}\text { CD33 } \\
\text { Antibody }\end{array}$ & $\begin{array}{l}9 / 1 / 2017 \\
\text { (reapproved) }\end{array}$ & $\begin{array}{l}\text { Newly } \\
\text { Dx }\end{array}$ & 280 & Phase III & $\begin{array}{l}2 \text { year OS } 53 \cdot 2 \% \\
\text { vs } 41.9 \%(H R \cdot 69 \\
P=0.0368)\end{array}$ \\
\hline $\begin{array}{l}\text { Gemtuzumab } \\
\text { ozogamicin (GO) }\end{array}$ & $\begin{array}{l}\text { CD33 } \\
\text { Antibody }\end{array}$ & $\begin{array}{l}9 / 1 / 2017 \\
\text { (reapproved) }\end{array}$ & $\begin{array}{l}\text { Newly } \\
\text { Dx }\end{array}$ & $\begin{array}{l}237 \text { (118 on } \\
\text { GO arm) }\end{array}$ & Phase III & $\begin{array}{l}\text { mOS } 4.9 \text { m vs } 3.6 \\
m(H R 0.69 \\
P=0.005)\end{array}$ \\
\hline $\begin{array}{l}\text { Gemtuzumab } \\
\text { ozogamicin (GO) }\end{array}$ & $\begin{array}{l}\text { CD33 } \\
\text { Antibody }\end{array}$ & $\begin{array}{l}9 / 1 / 2017 \\
\text { (reapproved) }\end{array}$ & $R / R$ & 57 & $\begin{array}{l}\text { Phase } \\
\text { II }\end{array}$ & $\begin{array}{l}\text { CR 26\% } \\
\text { mRFS } 11.6 \mathrm{~m}\end{array}$ \\
\hline Venetoclax & $\begin{array}{l}\text { BCL2 } \\
\text { Inhibitor }\end{array}$ & Not Approved & $R / R$ & 32 & $\begin{array}{l}\text { Phase } \\
\text { II }\end{array}$ & $\begin{array}{l}\text { ORR } 19 \% \\
\text { mOS } 4.7 \mathrm{~m}\end{array}$ \\
\hline
\end{tabular}

$\mathrm{FDA}=$ Food and drug administration; $\mathrm{R} / \mathrm{R}=$ Relapsed/refractory; $\mathrm{ORR}=$ Overall response rate; $\mathrm{CR}=$ Complete remission; $\mathrm{CRi}=\mathrm{Complete}$ remission with incomplete count recovery; $\mathrm{CRh}=$ Complete remission with partial hematologic recovery; $\mathrm{RFS}=$ Relapse free survival; $\mathrm{mOS}=\mathrm{Median}$ overall survival; $\mathrm{PL}=$ Placebo, $\mathrm{m}=$ months, $\mathrm{HR}=$ Hazard ratio.

\section{NPM1}

Nucleophosmin is a nucleolar phosphoprotein encoded by the NPM1 gene and regulates multiple cellular processes. The NPM1 gene has 12 exons and the protein product shuttles between the cytoplasm and the nucleus, although primarily residing in the nucleus. Nucleophosmin has a role in ribosome biogenesis, p53-dependent stress response, genomic stability and modulation of other growth-suppression pathways. Mutations in NPM1 involving exon 12 in the Cterminus of the protein lead to the expression of mutant cytoplasmic NPMc+, which is the most common mutation in AML and is always heterozygous (17). Recently, a study evaluating the exact leukemogenic effects of NPMc+ revealed that it also dislocates a transcription factor driver of monocyte differentiation PU.1 (also known as SPI1) into cytoplasm with it preventing collaboration with other master transcription factors CEBPA and RUNX1, thereby repressing terminal granulocytic differentiation (18).

NPM1 mutations are found in about $30 \%$ of AML patients and generally carry a favorable prognosis in the absence of FLT3-ITD, or when the FLT3-ITD allelic ratio is low. 


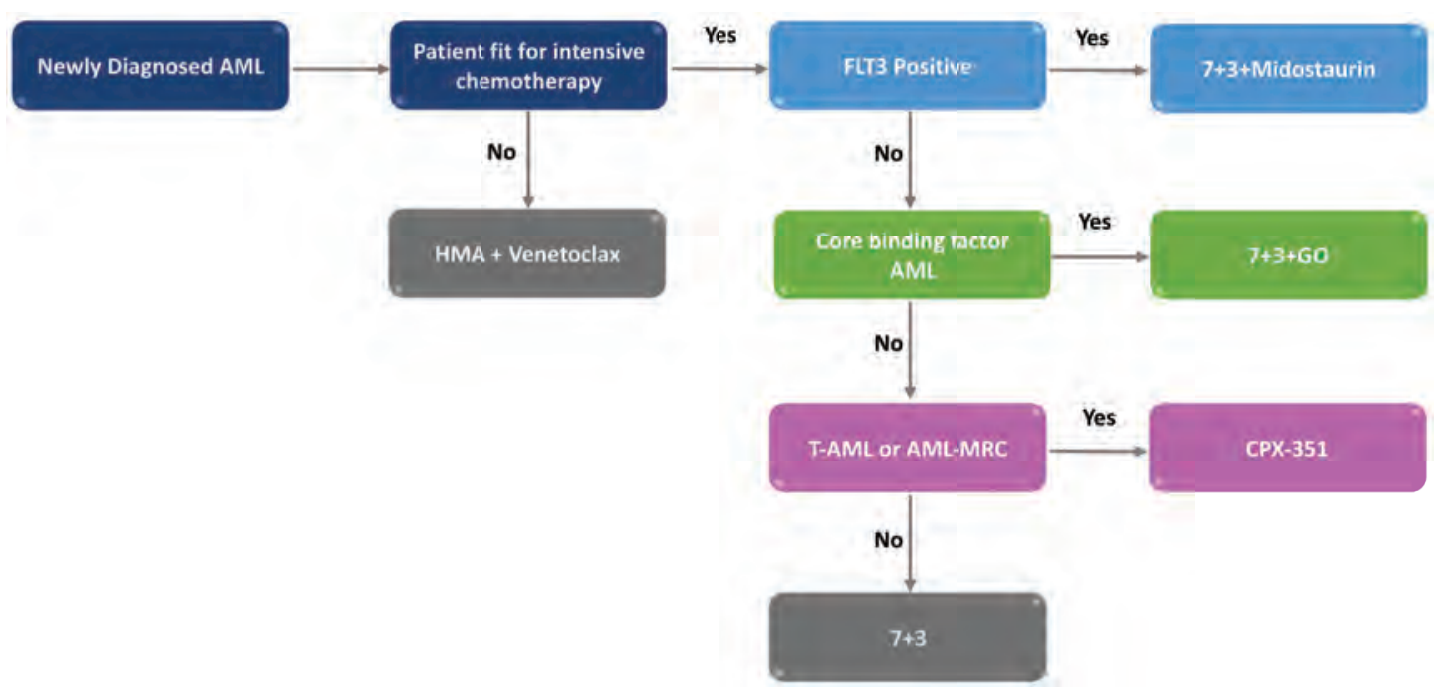

$1 \mathrm{~A}$

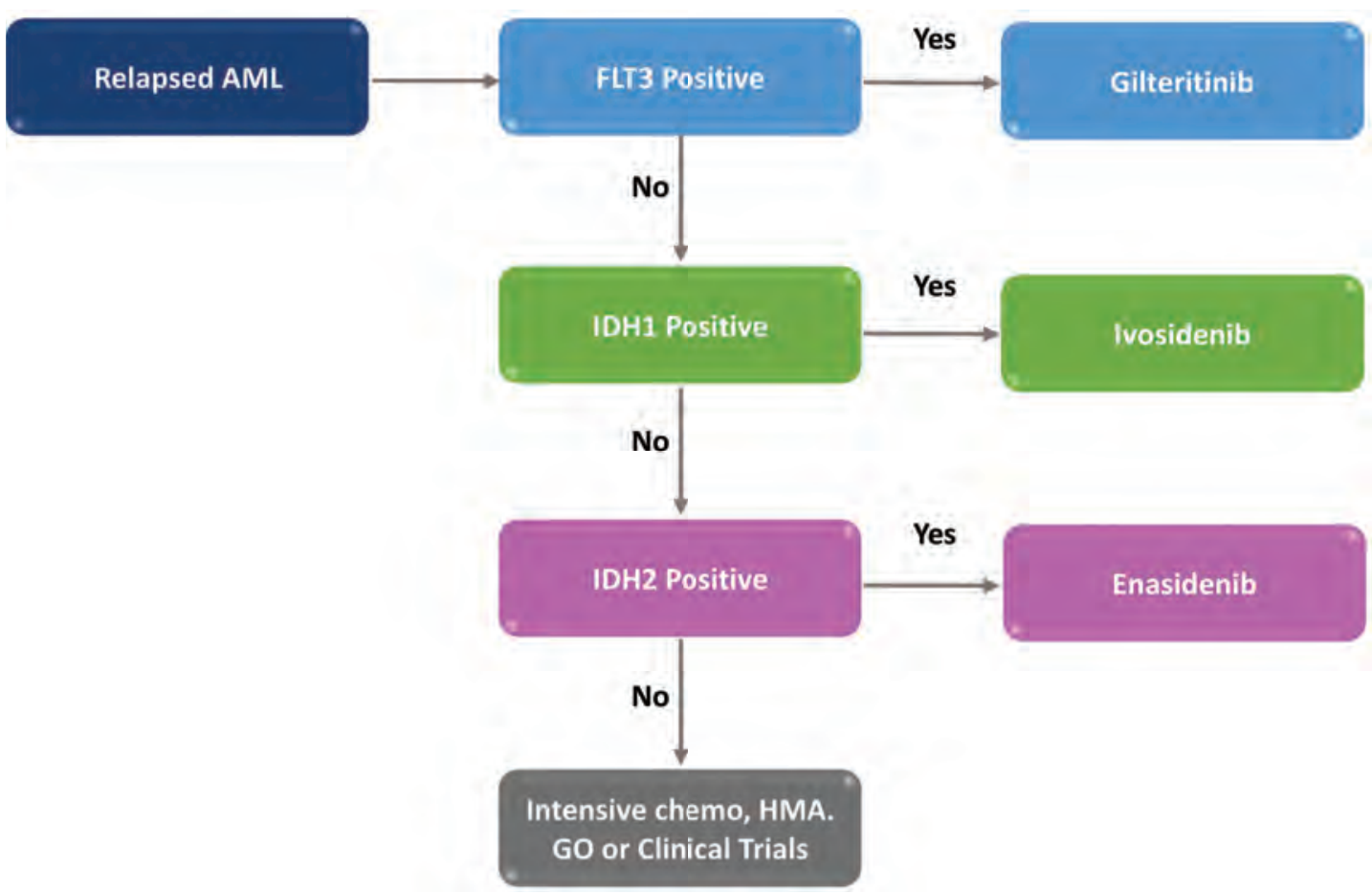

$1 \mathrm{~B}$

Figure 1. Treatment algorithm for patients with Newly Diagnosed (1A) and Relapsed AML using approved tar-


$\mathrm{AML} ; \mathrm{AML}-\mathrm{MRC}=\mathrm{AML}$ with myelodysplasia changes.

NPM1 mutations can co-occur with $D N$ MT3A, FLT3-ITD, IDH1/2 and TET2 but are mutually exclusive of RUNX1,CEPBA and TP53 $(12,17,19)$.

\section{CEBPA}

CCAAT/enhancer binding protein a $(C E B$ $P A)$ mutations occur in $5-10 \%$ of AML patients. Bi-allelic mutations constitute two 
thirds of mutations, involve mutations in the $\mathrm{N}$ - and $\mathrm{C}$ - terminus, and carry a favorable prognosis in AML (20). CEBPA is a transcription factor that binds both promoter and enhancer regions and plays a role in neutrophil differentiation (21). It is most commonly seen in patients with a normal karyotype and is recognized as a separate entity in the recent WHO classification $(5,22)$.

\section{Mutations in Methylation Pathway \\ DNMT3A}

DNA (cytosine-5)-methyltransferase $3 \mathrm{~A}$ is an enzyme that transfers methyl groups to specific CpG structures in the DNA regulating epigenetic changes. DNMT3A mutations occur in about $20-25 \%$ of patients with AML (23). The majority of somatic DNMT3A mutations occur at a single amino acid, R882. DNMT3A can co-occur with FLT3-ITD, NPM1, and IDH1/2 mutations is also rarely associated with transcription factor fusions such as $\mathrm{t}(8: 21)$, inv16 or $\mathrm{t}(15 ; 17)$. Most studies have associated DNMT3A mutations with worse outcomes, however some data suggest this can be overcome with higher anthracycline doses $(24,25)$.

\section{TET2}

Ten-eleven translocation 2 (TET2) is a methylcytosine dioxygenase 2 gene that encodes a protein involved in epigenetic modification by hydroxylation of the 5 ' end of the methyl cytosine residues (26). Mutations in TET2 are found in about $10 \%$ of AML, although TET2 mutations can occur in patients without evidence of hematologic malignancies where the incidence increases with age. This clonal hematopoiesis was shown to increase the risk of cardiovascular disease and death (27). The impact of TET2 mutations on outcomes and response to therapy in AML remains controversial (28).

\section{IDH1/IDH2}

Isocitrate dehydrogenase 1 and 2 are enzymes that catalyze the oxidative decarboxylation of isocitrate to 2-oxoglutarate and control DNA methylation and histone modification. $\mathrm{Mu}-$ tations in IDH1/2 lead to increased level of 2-hydroxyglutarate. IDH1 mutations occur in $5-10 \%$ affecting the arginine at either R132 or $\mathrm{R} 170$ residues and are exclusive of one another. IDH 2 mutations occur about $10 \%$ of AML affecting arginine residues R140 or R172 (29). Both $I D H 1$ and $I D H 2$ inhibitors have been developed and approved by the FDA for treatment of relapsed/refractory AML (Figure 1B), where they can be used as bridge for allogeneic hematopoietic cell transplantation in eligible patients $(30,31)$.

In August 2017, the first in class oral inhibitor of isocitrate dehydrogenase 2 (IDH2) enzyme, enasidenib (AG-221) received regulatory approval for relapse/refractory AML with an IDH2 mutation. Patients with relapsed/refractory AML received oral treatment daily and achieved an overall response rate of $40.3 \%$ with a median duration of response of 5.8 months (95\% CI $3.9-7.4)$. The median overall survival for all patients was 9.3 months (8.2-10.9 m), however median overall survival reached 19.7 months (11.6 $\mathrm{m}$ to not reached) for those who achieved a complete remission (19.3\%) (30) (Table 2). More recently, in July 2018, ivosidenib, an IDH1 inhibitor was approved by the FDA for the treatment of adult patients with IDH1 mutated relapsed/refractory AML. The overall response rate was $41.6 \%$ with $21.6 \%$ of patients achieving a CR. The median duration of responses were 6.5 months ( $95 \%$ CI, 4.6 to 9.3 ) and 9.3 months (95\% CI, 5.6 to 18.3 ) respectively $(31)$ (Table 2 ).

\section{Chromatin Modifying Genes}

\section{ASXL1}

Additional sex combs-like (ASXL) 1 gene is a chromatin modifying gene that encodes a 
binding protein what enhances or represses gene transcription. ASXL1 mutations occur in about $5 \%$ of de-novo AML and up to a quarter of patients with secondary AML. ASXL1 mutations have a negative impact on OS and have been classified as poor risk AML in the 2017 ELN risk stratification (2), although some reports showed that this impact may be lost when controlling for clinical and chromosomal abnormalities $(32,33)$.

\section{Tumor Suppressor Genes}

\section{TP53}

Tumor protein p53 (TP53) is a tumor suppressor gene located on the short arm of chromosome 17 and is involved in cell cycle regulation. Mutations are more common in secondary AML and are found in a quarter of patients, but only found in 5\% of patients with de novo disease (12). TP53 mutations are often associated with complex karyotype and carry a poor prognosis (34).

\section{WT1}

Wilms tumor (WT) 1 gene is a tumor suppressor gene. Overexpression of WT1 is common in hematopoietic myeloid malignancies and confers a higher chance of relapse and poor outcomes, even in the post allogeneic transplant setting. Some studies are investigating its use as a minimal residual disease marker to predict early relapses $(35,36)$.

\section{AML Risk Stratification (ELN 2017)}

The updated European Leukemia Net (ELN) recommendations for the diagnosis and management of AML were revised and published in 2017. The 2010 ELN risk stratification included mutations in CEBPA, NPM1 and FLT3. In the update version, 3 additional genomic abnormalities into the AML prognostication risk groups; these include
ASXL1, RUNX1 and TP53. Additionally, there has been a distinction in risk stratification based on FLT3-ITD allelic ratio, low defined as allelic ratio $<0.5$ or FLT3-ITD and high allelic ratio where the mutation burden is more than 0.5.Thus, the current AML risk stratification includes 3 risk categories based on genetics (i.e. cytogenetic and molecular abnormalities). Favorable risk group includes patients with core binding factor leukemia $[\mathrm{t}(8 ; 21$ and $\operatorname{inv}(16)$ or $\mathrm{t}(16 ; 16)]$, patients with biallelic mutated $C E P B A$ as well as mutated NPM1 without FLT3-ITD or with FLT3-ITD allelic ratio $<0.5$. The intermediate risk group includes patients with mutated NPM1 and FLT3-ITD allelic ratio of $>0.5$, wild type NPM1 with FLT3ITD negative of ratio $<0.5$ and $t(9 ; 11)$ and all other cytogenetic abnormalities that are not classified as favorable or adverse. The adverse risk group includes patients with the following cytogenetic abnormalities [ $t(6 ; 9)$, $\mathrm{t}(\mathrm{v} ; 11 \mathrm{q} 23.3) / K M T 2 A$ rearranged, $\mathrm{t}(9 ; 22)$, inv(3), chromosome 5,7 or $17 \mathrm{p}$ abnormalities] and molecular abnormalities [wild type NPM1 and FLT3-ITD ratio >0.5, mutated RUNX1, ASXL1 and TP53] (2). This stratification does not yet account for other cooccurring mutations or other mutational interactions, which may change in future prognostication systems.

\section{Conclusions}

Understanding genomics in AML is prudent for risk stratification and making treatment decisions; further characterization of mutational interactions, the impact on prognosis and treatment responses as well as translating genomic testing, such as MRD testing, into clinically meaningful therapeutic interventions is necessary to further advance therapies and improve outcomes. To date, the risk stratification of AML is dependent on incorporating a few mutations as FLT3, NPM1, CEBPA, RUNX1, and TP53 into each 
risk category, thus mutational analysis using widely available myeloid gene panels has become standard of care for all newly diagnosed patients. These are important to guide optimal outcomes, treatment planning for upfront hematopoietic cell transplantation. The co-occurrence of gene mutations and disease heterogeneity mandate the use of newer analytic techniques to better personalize management for each of our patients.

Authors' Contributions: Conception and design: YFM, AN and MEK; Acquisition, analysis and interpretation of data: YFM, AN and MEK; Drafting the article: YFM; Revising it critically for important intellectual content: MEK and AN; Approved final version of the manuscript: YFM, MEK and AN.

Conflict of Interest: The authors declare that they have no conflict of interest.

\section{References}

1. Dohner H, Weisdorf DJ, Bloomfield CD. Acute Myeloid Leukemia. N Engl J Med. 2015;373(12):1136-52.

2. Dohner H, Estey E, Grimwade D, Amadori S, Appelbaum FR, Buchner T, et al. Diagnosis and management of AML in adults: 2017 ELN recommendations from an international expert panel. Blood. 2017;129(4):424-47.

3. Hussaini MO, Mirza AS, Komrokji R, Lancet J, Padron E, Song J. Genetic Landscape of Acute Myeloid Leukemia Interrogated by Next-generation Sequencing: A Large Cancer Center Experience. Cancer genomics \& proteomics. 2018;15(2):121-6.

4. Cheng HC, Liu SW, Liu Y, Zhao XF, Li W, Qiu L, et al. Application of Next Generation Sequencing for AML/MDS Diagnosis and Treatment [in Chinese]. Zhongguo Shi Yan Xue Ye Xue Za Zhi. 2017;25(6):1631-5.

5. Arber DA, Orazi A, Hasserjian R, Thiele J, Borowitz MJ, Le Beau MM, et al. The 2016 revision to the World Health Organization classification of myeloid neoplasms and acute leukemia. Blood. 2016;127(20):2391-405.

6. Nacheva EP, Grace CD, Brazma D, Gancheva K, Howard-Reeves J, Rai L, et al. Does BCR/ABL1 positive acute myeloid leukaemia exist? $\mathrm{Br} \mathrm{J}$ Haematol. 2013;161(4):541-50.

7. Konoplev S, Yin CC, Kornblau SM, Kantarjian HM, Konopleva M, Andreeff M, et al. Molecular characterization of de novo Philadelphia chromo- some-positive acute myeloid leukemia. Leuk Lymphoma. 2013;54(1):138-44.

8. Groschel S, Sanders MA, Hoogenboezem R, de Wit E, Bouwman BAM, Erpelinck C, et al. A single oncogenic enhancer rearrangement causes concomitant EVI1 and GATA2 deregulation in leukemia. Cell. 2014;157(2):369-81.

9. Yamazaki H, Suzuki M, Otsuki A, Shimizu R, Bresnick EH, Engel JD, et al. A remote GATA2 hematopoietic enhancer drives leukemogenesis in inv(3)(q21;q26) by activating EVI1 expression. Cancer Cell. 2014;25(4):415-27.

10. Grimwade D, Ivey A, Huntly BJ. Molecular landscape of acute myeloid leukemia in younger adults and its clinical relevance. Blood. 2016;127(1):2941.

11. Papaemmanuil E, Gerstung M, Bullinger L, Gaidzik VI, Paschka P, Roberts ND, et al. Genomic Classification and Prognosis in Acute Myeloid Leukemia. N Engl J Med. 2016;374(23):2209-21.

12. Cancer Genome Atlas Research N, Ley TJ, Miller C, Ding L, Raphael BJ, Mungall AJ, et al. Genomic and epigenomic landscapes of adult de novo acute myeloid leukemia. N Engl J Med. 2013;368(22):2059-74.

13. Ding L, Ley TJ, Larson DE, Miller CA, Koboldt DC, Welch JS, et al. Clonal evolution in relapsed acute myeloid leukaemia revealed by whole-genome sequencing. Nature. 2012;481(7382):50610.

14. Lindsley RC, Mar BG, Mazzola E, Grauman PV, Shareef S, Allen SL, et al. Acute myeloid leukemia ontogeny is defined by distinct somatic mutations. Blood. 2015;125(9):1367-76.

15. Nazha A, Zarzour A, Al-Issa K, Radivoyevitch T, Carraway HE, Hirsch CM, et al. The complexity of interpreting genomic data in patients with acute myeloid leukemia. Blood Cancer J. 2016;6(12):e510.

16. Levis M. FLT3 mutations in acute myeloid leukemia: what is the best approach in 2013? Hematology Am Soc Hematol Educ Program. 2013;2013:220-6.

17. Stone RM, Mandrekar SJ, Sanford BL, Laumann K, Geyer S, Bloomfield CD, et al. Midostaurin plus Chemotherapy for Acute Myeloid Leukemia with a FLT3 Mutation. N Engl J Med. 2017;377(5):45464.

18. Heath EM, Chan SM, Minden MD, Murphy T, Shlush LI, Schimmer AD. Biological and clinical consequences of NPM1 mutations in AML. Leukemia. 2017;31(4):798-807.

19. Gu X, Ebrahem Q, Mahfouz RZ, Hasipek M, Enane $\mathrm{F}$, Radivoyevitch $\mathrm{T}$, et al. Leukemogenic nu- 
cleophosmin mutation disrupts the transcription factor hub that regulates granulomonocytic fates. J Clin Invest. 2018;128(10):4260-79.

20. Meani N, Alcalay M. Role of nucleophosmin in acute myeloid leukemia. Expert Rev Anticancer Ther. 2009;9(9):1283-94.

21. Mannelli F, Ponziani V, Bencini S, Bonetti MI, Benelli M, Cutini I, et al. CEBPA-double-mutated acute myeloid leukemia displays a unique phenotypic profile: a reliable screening method and insight into biological features. Haematologica. 2017;102(3):529-40.

22. Ohlsson E, Schuster MB, Hasemann M, Porse BT. The multifaceted functions of C/EBPalpha in normal and malignant haematopoiesis. Leukemia. 2016;30(4):767-75.

23. Martelli MP, Sportoletti P, Tiacci E, Martelli MF, Falini B. Mutational landscape of AML with normal cytogenetics: biological and clinical implications. Blood Rev. 2013;27(1):13-22.

24. Ibrahem L, Mahfouz R, Elhelw L, Abdsalam EM, Soliman R. Prognostic significance of DNMT3A mutations in patients with acute myeloid leukemia. Blood Cells Mol Dis. 2015;54(1):84-9.

25. Guryanova OA, Shank K, Spitzer B, Luciani L, Koche RP, Garrett-Bakelman FE, et al. DNMT3A mutations promote anthracycline resistance in acute myeloid leukemia via impaired nucleosome remodeling. Nat Med. 2016;22(12):1488-95.

26. Sehgal AR, Gimotty PA, Zhao J, Hsu JM, Daber R, Morrissette JD, et al. DNMT3A Mutational Status Affects the Results of Dose-Escalated Induction Therapy in Acute Myelogenous Leukemia. Clin Cancer Res. 2015;21(7):1614-20.

27. Zhang TJ, Zhou JD, Yang DQ, Wang YX, Wen XM, Guo $\mathrm{H}$, et al. TET2 expression is a potential prognostic and predictive biomarker in cytogenetically normal acute myeloid leukemia. J Cell Physiol. 2018;233(8):5838-46.

28. Jaiswal S, Fontanillas P, Flannick J, Manning A, Grauman PV, Mar BG, et al. Age-related clonal hematopoiesis associated with adverse outcomes. N Engl J Med. 2014;371(26):2488-98.

29. Gaidzik VI, Paschka P, Spath D, Habdank M, Kohne $\mathrm{CH}$, Germing U, et al. TET2 mutations in acute myeloid leukemia (AML): results from a comprehensive genetic and clinical analysis of the AML study group. J Clin Oncol. 2012;30(12):13507.

30. Abbas S, Lugthart S, Kavelaars FG, Schelen A, Koenders JE, Zeilemaker A, et al. Acquired mutations in the genes encoding IDH1 and IDH2 both are recurrent aberrations in acute myeloid leukemia: prevalence and prognostic value. Blood. 2010;116(12):2122-6.

31. Stein EM, DiNardo CD, Pollyea DA, Fathi AT, Roboz GJ, Altman JK, et al. Enasidenib in mutant IDH2 relapsed or refractory acute myeloid leukemia. Blood. 2017;130(6):722-31.

32. Schnittger S, Eder C, Jeromin S, Alpermann T, Fasan A, Grossmann V, et al. ASXL1 exon $12 \mathrm{mu}$ tations are frequent in AML with intermediate risk karyotype and are independently associated with an adverse outcome. Leukemia. 2013;27(1):82-91.

33. Patel JP, Gonen M, Figueroa ME, Fernandez H, Sun Z, Racevskis J, et al. Prognostic relevance of integrated genetic profiling in acute myeloid leukemia. N Engl J Med. 2012;366(12):1079-89.

34. Seifert H, Mohr B, Thiede C, Oelschlagel U, Schakel U, Illmer T, et al. The prognostic impact of $17 \mathrm{p}$ (p53) deletion in 2272 adults with acute myeloid leukemia. Leukemia. 2009;23(4):656-63.

35. Yoon JH, Kim HJ, Shin SH, Yahng SA, Lee SE, Cho BS, et al. Serial measurement of WT1 expression and decrement ratio until hematopoietic cell transplantation as a marker of residual disease in patients with cytogenetically normal acute myelogenous leukemia. Biol Blood Marrow Transplant. 2013;19(6):958-66.

36. Malagola M, Skert C, Ruggeri G, Turra A, Ribolla R, Cancelli V, et al. Peripheral blood WT1 expression predicts relapse in AML patients undergoing allogeneic stem cell transplantation. Biomed Res Int. 2014;2014:123079. 